\title{
Evaluation of hemangioma management in Erbil city
}

\begin{tabular}{c}
\hline Jalal Hamasalih Fattah * Wesam Amjad Kaka ** \\
\hline Abstract
\end{tabular}

Background and objective: The term hemangioma refers to the common tumor of infancy that exhibits rapid postnatal growth and slow regression during childhood. Hemangioma has a perinatal incidence of $1 \%-3 \%$ and affecting $10 \%$ of infants by one year of age. The aim of this study was to evaluate treatment outcomes following various managements of hemangiomas.

Methods: One hundred four patients were included in this prospective study. Based on clinical management, each patient was assigned to different treatment groups: steroid, surgical, and combined therapy. Treatment outcomes were evaluated based on improvement in size and color, by a blinded panel of three raters including two doctors and one patient or patient's parents. Finally, comparison of outcomes between groups was analyzed statistically. A p value $\leq 0.05$ was considered statistically significant.

Results: The results revealed that there was reduction in size and improvement in color following intervention in each group. Comparison of treatment outcomes between treatment groups revealed statistically significant difference among the groups regarding improvement in color $(P<0.01)$ and reduction in size of hemangioma $(P<0.01)$, and surgical treatment was better (among 31 patients, 17 got moderate improvement and 11 excellent improvement) compared with steroid therapy (among 36 patients, 19 got moderate improvement, and 3 excellent improvement).

Conclusion: A favorable outcome can be achieved following appropriate intervention during all stages of development of hemangiomas.

Keywords: Hemangioma, steroid, surgical excision.

\section{Introduction}

The term hemangioma refers to the common tumor of infancy that exhibits rapid postnatal growth and slow regression during childhood. ${ }^{1}$ Hemangioma is the most common tumor in infancy, with a perinatal incidence of $1 \%-3 \%$ and affecting $10 \%$ of infants by one year of age. ${ }^{2}$ Up to $30 \%$ of preterm infants with low birth weight $(1,000$ g) may have hemangioma. A predilection for the female sex has been reported, with a ratio of $2-5: 1 .^{3,4}$ The initial sign of hemangioma is either an erythematous macular patch, a blanched spot, or a localized telangiectasia, surrounded by a pale halo. ${ }^{5}$ The hallmark of hemangiomas is rapid growth during the first several months of the child's life. When involution occurs, the process is usually completed by the child's $7^{\text {th }}$ year. Therefore, a strong opinion developed in the middle $20^{\mathrm{th}}$ century that appropriate treatment for hemangioma was no treatment, which became known as "benign neglect." However, symptomatic problems such as ulceration, bleeding, infection, and residual skin changes which may be disfiguring and require early intervention. ${ }^{6}$ Also, children begin to develop self-awareness at 18-24 months of age. ${ }^{7}$ Therefore, the psychosocial impact on a child with facial hemangiomas or its resultant scar cannot be underestimated. ${ }^{8}$ The past decade has witnessed a revolution in the

* Department of Plastic surgery, College of Medicine, Hawler Medical University, Erbil, Iraq.

** Department of Pediatric surgery, College of Medicine, Hawler Medical University, Erbil, Iraq. 
http://dx.doi.org/10.15218/zjms.2014.0041

understanding and treatment of these vascular lesions. Previous complacency in treatment is changing to a more proactive approach to circumvent immanent esthetic sequelae. ${ }^{9}$ Anatomic location, lesion size, and patient age are three important drivers in the decision of whether to intervene. A nickel-size lesion on the tip of a newborn nose poses a different problem from the same lesion located at the base of the occiput; a $3-\mathrm{cm}$ hemangioma in a perineal fold is more likely to ulcerate and become infected than an identical subclavicular lesion. Similarly, the size or footprint of the hemangioma impacts the decision of whether to intervene. Many parents will tolerate a 3-mm bright red spot on their child's forehead, but few will accept a 3-cm lesion in the same location. Patient age is another factor that affects the decision of whether to intervene. It may be reasonable to observe a 3-month-old child with a hemangioma, whereas the same lesion might best be resected in a 13-month-old child to achieve the best aesthetic outcome. ${ }^{10}$ A number of treatment modalities are available for the management of hemangiomas. These include observation, corticosteroids (systemic, intralesional), sclerotherapy, interferon $2 \alpha$, laser therapy, vincristine, Beta-blockers, and surgical treatment. ${ }^{11}$ The aim of this study was to identify those lesions that are most likely to require treatment and how to select the treatment modality that is best suited for a particular individual with emphasis on the timing of intervention, particularly focusing on outcomes following various managements (steroid or surgical treatment), to enable plastic and maxillofacial surgeon to develop an approach in the management of these esthetically, functionally, and psychosocially compromising congenital vascular tumor.

\section{Methods}

\section{Design and sample collection:}

This is a prospective study conducted in Erbil City, Kurdistan Region, Iraq in the Department of Plastic and Reconstruction
Surgery in Rezgary Teaching Hospital and Rapareen Pediatric Hospital from March 2009 to April 2013. A total sample of 104 patients with hemangioma managed in the above mentioned hospitals were included in this study. The following information was recorded from each patient: age, sex, onset of hemangioma, anatomic location, size, complications presented during initial consultation, type of treatment, and time period of treatment. Treatment plan was based on the age of patient; phase, type, size, location of hemangiomas; and the patient's complaints. The protocol for management of hemangiomas was based on the algorithm suggested by Williams et $\mathrm{al}^{9}$ of observation, steroid, surgical excision or combined therapy. Observation selected for silent small, localized hemangioma that do not involve aesthetically or functionally important areas. Infants were followed closely, on a monthly basis. Steroids were recommended for children up to the age of 18-20 months, i.e., during the proliferative phase of hemangiomas. Intralesional injection of triamcinolone acetonide ( 3 to $5 \mathrm{mg} /$ $\mathrm{kg}$ per procedure) was advised for focal hemangiomas and those causing obstruction of orifices such as periorbital hemangiomas. The injection should be with low injection pressure and no digital pressure after the procedure. The injections were repeated at monthly intervals to evaluate the response. Usually three to five injections were needed and were terminated when no further response in treatment was noticed. Oral corticosteroids in the form of prednisolone were recommended for rapidly proliferating large hemangiomas at an initial dose of $4 \mathrm{mg} / \mathrm{kg}$ body weight. The hemangiomas were reevaluated for steroid response after a week. If change in size of hemangioma was evident at that time, the treatment was maintained at the initial dose for three more weeks and then tapered over a period of 4-8 weeks. The patients were then followed at monthly intervals to evaluate the response and discontinued by 10 to 11 months. Surgical excision was recommended mainly for 
http://dx.doi.org/10.15218/zjms.2014.0041

involuted hemangiomas, and sometimes for proliferative hemangiomas. In proliferative phase, excision was advised for steroid nonresponders, periorbital hemangiomas, and ulcerated hemangiomas.
Ethical considerations: The study protocol was approved by the Research Ethics Committee of the College of Medicine of Hawler Medical University. Informed consent was obtained from parents.

Table 1: Distribution of hemangioma.

\begin{tabular}{lll}
\hline Site of hemangioma & No & $\%$ \\
\hline Scalp & 7 & 6.7 \\
Forehead & 13 & 12.5 \\
Eyelid & 5 & 4.8 \\
Cheek & 14 & 13.5 \\
Nose & 10 & 9.6 \\
Post auricular & 5 & 4.8 \\
Lip & 22 & 21.2 \\
Upper limb & 4 & 3.8 \\
Trunk & 11 & 10.6 \\
Perineal & 3 & 2.9 \\
Lower limb & 6 & 5.8 \\
Diffuse & 4 & 3.8 \\
Total & 104 & 100 \\
\hline
\end{tabular}

Reconstruction of defect after excision of hemangioma was carried out by primary closure, or local flaps. The distribution of hemangioma is shown in Table 1. Lip was the most common site.

Patients were followed up to analyze the post-treatment outcome based on the improvement in size and color of the hemangioma. The follow up findings were reported and analyzed, photographs have been taken for all patients in each visits. Treatment outcomes were assessed by three raters, including two physicians and one patient or patient's parents, and were graded as poor (score 0), fair (score 1), good (score 2), and excellent (score 3). The average of individual scores given by each rater was taken. Percentage improvement for each patient was calculated using the following scale: 1) minimal improvement (0\%-25\%); 2) mild improvement $(26 \%-50 \%)$; 3) moderate improvement (51\%-75\%); and 4) excellent improvement $(76 \%-100 \%)$. Results of each of these parameters were summarized by groups.
Statistical analysis: Data were analyzed using the Statistical Package for the Social Sciences (version 19). Chi square test of association was used to compare between proportions. Fisher exact test was used when the expected count of more than $20 \%$ of the cells of the table was less than 5. A $P$ value of $\leq 0.05$ was considered statistically significant.

\section{Results}

The age of the patients at the time of initial consultation ranged from one month to thirteen years, the mean age was three years. The hemangiomas arose within the $1^{\text {st }}$ month after birth in $76 \%$ of patients. The gender distribution was 70 female and 34 male. The complications presented during initial consultation and their management are shown in Table 2. The commonest complication was ulceration (17 patients). 
Surgical excision was carried out for management of hemangiomas in 32 patients (Table 2). The final results of each of the treatment group are summarized in Table 3 . Table 3 shows statistically significant difference among the groups regarding improvement in size and color of hemangioma $(P<0.01)$. Surgical treatment was better compared with steroid therapy.

Table 2: The complications during initial consultation.

\begin{tabular}{|c|c|c|c|c|c|c|c|c|c|c|c|c|c|}
\hline \multirow{3}{*}{ Complications } & \multicolumn{4}{|c|}{ Management } & & & & & & & \multirow{2}{*}{\multicolumn{2}{|c|}{ Total }} & \multirow[b]{3}{*}{$p$ value } \\
\hline & \multicolumn{2}{|c|}{ Observation } & \multicolumn{2}{|c|}{$\begin{array}{l}\text { Local } \\
\text { steroid }\end{array}$} & \multicolumn{2}{|c|}{$\begin{array}{l}\text { Systemic } \\
\text { steroid }\end{array}$} & \multicolumn{2}{|c|}{ Surgery } & \multicolumn{2}{|c|}{ Combined } & & & \\
\hline & No & $\%$ & No & $\%$ & No & $\%$ & No & $\%$ & No & $\%$ & No & $\%$ & \\
\hline No Comp. & 29 & 28 & 4 & 3.8 & 15 & 14.4 & 5 & 4.8 & 2 & 1.9 & 55 & 52.9 & \\
\hline Ulceration & 0 & 0 & 2 & 1.9 & 5 & 4.8 & 9 & 8.6 & 1 & 0.9 & 17 & 16.4 & \\
\hline Bleeding & 0 & 0 & 0 & 0 & 0 & 0 & 5 & 4.8 & 0 & 0 & 5 & 4.8 & 0.003 \\
\hline Obstruction & 0 & 0 & 4 & 3.8 & 5 & 4.8 & 4 & 3.8 & 2 & 1.9 & 15 & 14.4 & \\
\hline Infection & 1 & 0.9 & 0 & 0 & 0 & 0 & 0 & 0 & 0 & 0 & 1 & 0.9 & \\
\hline $\begin{array}{l}\text { Fibrofatty } \\
\text { residium }\end{array}$ & 2 & 1.9 & 0 & 0 & 0 & 0 & 9 & 8.6 & 0 & 0 & 11 & 10.6 & \\
\hline Total & 32 & 30.8 & 10 & 9.6 & 25 & 24 & 32 & 30.8 & 5 & 4.8 & 104 & 100 & \\
\hline
\end{tabular}

Table 3: The percentage of improvement of hemangioma.

\begin{tabular}{|c|c|c|c|c|c|c|c|c|c|c|c|}
\hline \multirow[t]{2}{*}{ Management } & \multicolumn{2}{|c|}{$\begin{array}{l}\text { Minimal } \\
\text { improvement } \\
\text { (up to } 25 \% \text { ) }\end{array}$} & \multicolumn{2}{|c|}{$\begin{array}{l}\text { Mild } \\
\text { improvement } \\
(26 \%-50 \%)\end{array}$} & \multicolumn{2}{|c|}{$\begin{array}{l}\text { Moderate } \\
\text { improvement } \\
(51 \%-75 \%)\end{array}$} & \multicolumn{2}{|c|}{$\begin{array}{l}\text { Excellent } \\
\text { improvement } \\
(76 \%-100 \%)\end{array}$} & \multicolumn{2}{|c|}{ Total } & \multirow[t]{2}{*}{$p$ value } \\
\hline & No & $\%$ & No & $\%$ & No & $\%$ & No & $\%$ & No & $\%$ & \\
\hline Observation & 7 & 6.8 & 18 & 17.3 & 5 & 4.8 & 2 & 1.9 & 32 & 30.8 & \\
\hline Local steroid & 1 & 0.9 & 3 & 2.9 & 5 & 4.8 & 1 & 0.9 & 10 & 9.6 & \\
\hline Systemic & 3 & 2.8 & 7 & 6.7 & 14 & 13.4 & 2 & 1.9 & 26 & 25 & \\
\hline steroid & & & & & & & & & & & 0.004 \\
\hline Surgery & 0 & 0 & 3 & 2.9 & 17 & 16.3 & 11 & 10.6 & 31 & 29.8 & \\
\hline Combined & 0 & 0 & 1 & 0.9 & 1 & 0.9 & 3 & 2.8 & 5 & 4.8 & \\
\hline Total & 11 & 10.5 & 32 & 30.7 & 42 & 40.4 & 19 & 18.3 & 104 & 100 & \\
\hline
\end{tabular}




\section{Discussion}

Hemangiomas are a group of pediatric vascular tumors usually appearing soon after birth in $60 \%-70 \%$ of patients. ${ }^{12}$ This was evident in the present study also, as the hemangiomas arose within the $1^{\text {st }}$ month after birth in $76 \%$ of patients. The ratio of female to male in our group of patients was $2: 1$, which was similar to the ratio generally reported in the literature of $2-5: 1 .^{10,12,13}$ The management of hemangiomas has been a subject of intense controversy for many decades. They are remarkably heterogeneous regarding size, location, and rate of growth and involution. Despite the benign and trivial nature of most hemangiomas, a significant minority cause functional compromise or permanent disfigurement. They are also notoriously unpredictable early in infancy because some barely grow whereas others blossom forth into huge tumors. ${ }^{14,15} \mathrm{We}$ therefore undertook a review of our patients to evaluate the treatment outcomes following various managements of hemangiomas, remembering that the comparison of ways of treatment is significant when all variables are fixed (size, site, age). Our study revealed a favorable outcome after steroid therapy regarding to reduction in size of tumor, and improvement in color. The age of the patients in this group ranged from three months to one and half year. Thus, steroids form the mainstay of treatment of hemangiomas during the proliferative phase, ${ }^{9}$ with intralesional therapy for localized and periorbital hemangiomas ${ }^{16,17}$ and systemic therapy for large and diffusel hemangiomas $^{17,18}$ (Figure 1 and 2).
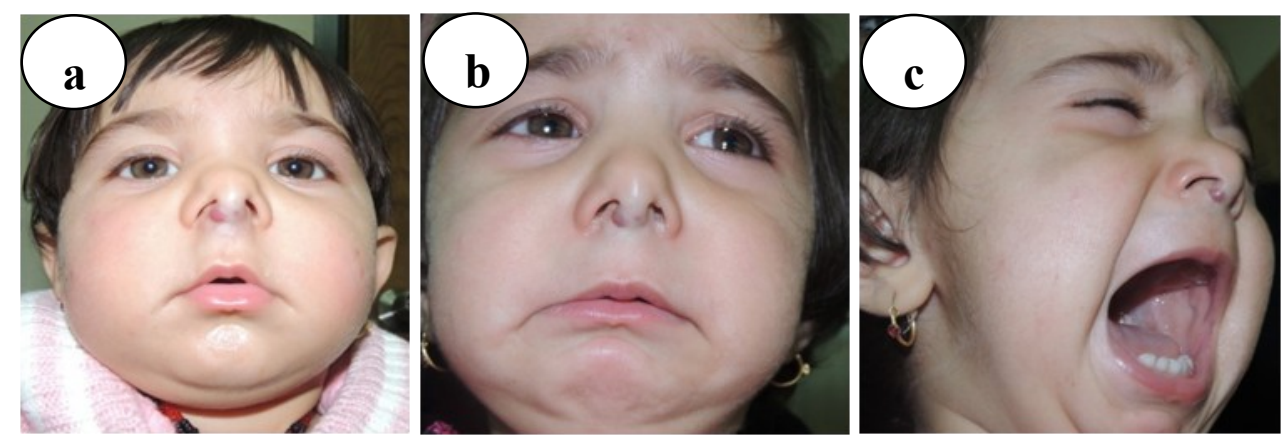

Figure 1: a- Pretreatment photograph of 8 month infant with hemangioma at the columalla causing obstruction of right nostril, $b$ - same patient after three injections of Triamcinolone acetonide showing moderate improvement with release of the obstruction, c- moderate improvement in oblique view.
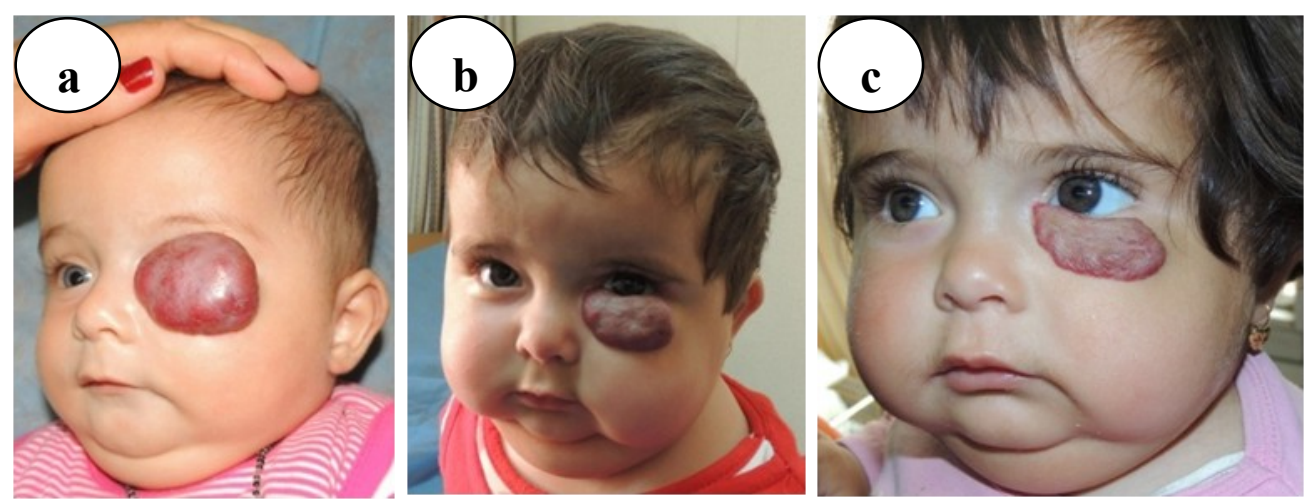

Figure 2: a- Pretreatment photograph of 6 month infant with hemangioma at the left suborbital area causing complete obstruction of vision, b- same patient after one month of oral steroid showing mild improvement, c- moderate improvement after eight months. 
http://dx.doi.org/10.15218/zjms.2014.0041

Surgical excision was carried out for the management of hemangiomas during the involutive phase and resulted in improved outcomes. Surgical excision plays an important role for management of hemangiomas causing functional problems, psychologic distress, and resection of fibrofatty tissue. In retrospective studies of the management of hemangiomas done by Achauer et $\mathrm{al}^{14}$ and Demiri et $\mathrm{al}^{19}$, excisional surgery and reconstruction produced excellent results. Thus, surgery can provide active treatment with excellent results and minimal morbidity (Figure 3 ).
Combined modality approach for the management of significantly large hemangiomas also resulted in an improved outcome in a majority of patients (80\% moderate to excellent improvement), with steroids and surgical excision (Figure 4). Studies by Achauer et al, ${ }^{14}$ Demiri et al ${ }^{19}$ and Kane et al, $^{20}$ also showed improved outcome with combined treatment approach. Thus, significantly large and problematic hemangiomas can be managed with a combination of medical and surgical treatment modalities.

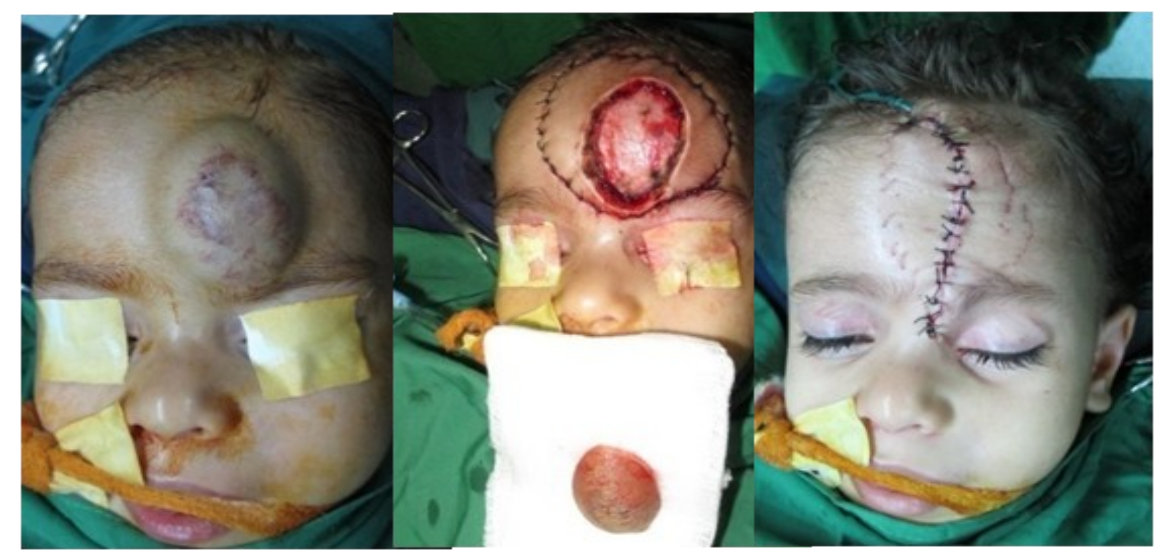

Figure 3: a- Pretreatment photograph of 2 year child with forehead hemangioma, b- complete surgical excision, c- primary wound closure with excellent improvement.
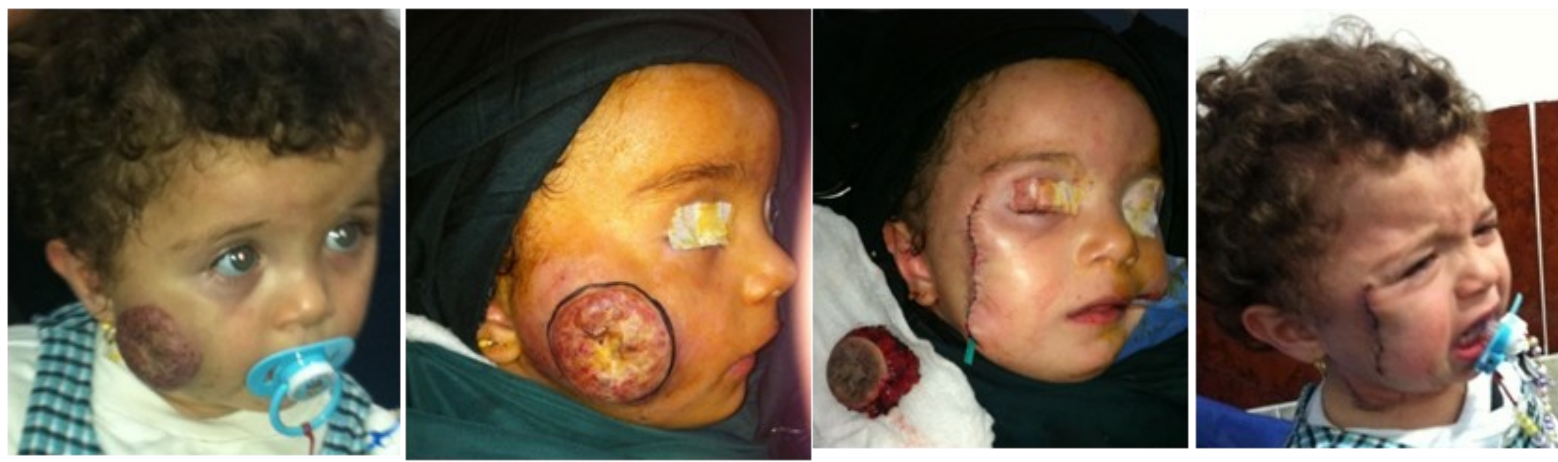

Figure 4: a- Pretreatment photograph of 4 year child with cheek hemangioma which failed to respond to steroid with history of bleeding, b- Marking for surgical excision c \& d- complete hemangioma excision and primary wound closure with excellent improvement and intact facial nerve. 
http://dx.doi.org/10.15218/zjms.2014.0041

The present study demonstrated a large non-treatment rate of complications at initial consultation of $47 \%$ (49 patients), which can be attributed to the fact that these patients seek treatment after complications had developed. However, this large rate warrants the need for awareness through community based camps and other measures regarding the need for intervention. Fibrofatty masses of tissue were observed in 11 patients $(10.5 \%)$. This concluded the observation that hemangiomas, if allowed to involute, leave excess fibrofatty skin residium. ${ }^{8,21}$ Obstruction of orifices was present in 15 patients $(14 \%)$, ulceration in 17 patients $(16 \%)$, bleeding in 5 patients $(4.8 \%)$ and infection occurred in one patient $(0.9 \%)$. Thus, it can be concluded that obstruction and ulceration are the most common indications for management of hemangiomas during the proliferative phase. ${ }^{9,21}$ Comparison of treatment outcomes between treatment groups revealed that there was significant difference in outcome among various treatment groups. This can be explained on the basis that surgical excision and combined approach eliminated hemangioma more completely. In the present study we emphasize that an early diagnosis and active intervention is important, because these lesions initially presenting as a macular rash can grow rapidly to cause functional compromise, and if left untreated they leave a residue resulting in an esthetic compromise.

\section{Conclusion}

A favorable outcome can be achieved following appropriate intervention during all stages of development of hemangioma.

\section{Conflicts of interest}

The authors report no conflicts of interest.

\section{References}

1. Mulliken B, Fishman J, Burrows E. Vascular anomalies. Curr Pro Surg 2000; 37:517.

2. Chamlin L. Multicenter prospective study of ulcerated hemangiomas. J Pediatrics 2007; 114:684-9.
3. Kleiman A, Keats C, Chan G, Khan A. Evolutionof hemangioma endothelium. Exp Mol Pathol 2012; 93:264-72.

4. Bischoff J. Progenitor cells in infantile hemangioma. J Cranio- fac Surg 2009; 20 (Suppl1):695-7.

5. Tollefson M, Frieden J. Early growth of infantile hemangiomas: what parents' photographs tell us. J Pediatrics 2012; 130:314-20.

6. Finn C, Glowacki J, Mulliken B. Congenital vascular lesions: clinical application of a new classification. J Pediatr Surg1983; 18:894-900.

7. Dieterich A, Cohen A, Liggett J. Behavioral adjustment and self concept of young children with hemangiomas. Pediatr Dermatol 1992; 9:241-5.0

8. Williams F, Hochman M, Rodgers J, Brockbank D, Shannon L, Lam M. A psychological profile of children and families afflicted with hemangiomas. Arch Facial Plast Surg 2003; 5:229-34.

9. Williams F, Stanislaw P, Dupree M, Mourtizkos K, Mihm M, Shannon L. Hemangiomas in infants and children: an algorithm for intervention. Arch Facial Plast Surg 2000; 2:103-11.

10. Aaron Fay, John Nguyen, Milton Waner. Conceptual Approach to the Management of Infantile Hemangiomas. J Pediatr 2010; 157 (6):881-8.

11. Eivazi $B$, Cremer $H$, Mangold $C$, Teymoortash $A$, Wiegand S, Werner J. Hemangiomas of the nasal tip: An approach to a therapeutic challenge. Int J Pediatr Otorhinolaryngol 2011; 75:368-75.

12. Mulliken B, Glowacki J. Hemangiomas and vascular malformations in infants and children: a classification based on endothelial characteristics. Plast Reconstr Surg 1982; 69:412-20.

13. Enjolras O, Gelbert F. Superficial hemangiomas: associations and management. Pediatr Dermatol 1997; 14:173-9.

14. Achauer M, Chang J, Vander M. Management of hemangioma of infancy: review of 245 patients. Plast Reconstr Surg 1997; 99:1301-8.

15. Mcheika N, Renauld V, Duportb G, Vergnesc P, Levarda G. Surgical treatment of haemangioma in infants. Br J Plast Surg 2005; 58:1067-72.

16. Jalil S, Akhtar J, Ahmed S. Corticosteroids therapy in the management of infantile cutaneous hemangiomas. J Coll Physicians Surg Pak 2006; 16:662-5.

17. Pope E, Krafchik R, Macarthur C. Oral versus high-dose pulse corticosteroids for problematic infantile hemangiomas: a randomized, controlled trial. J Pediatrics 2007; 119:1239-47.

18. Bennett L, Fleischer B, Chamlin L, Frieden J. Oral corticosteroid use is effective for cutaneous hemangiomas. An evidence based evaluation. Arch Dermatol 2001; 137:1208-13.

19. Demiri C, Pelissies P, Genin T, Tsakoniatis N, Martin D, Baudet J. Treatment of facial haemangiomas: the present status of surgery. $\mathrm{Br} \mathrm{J}$ Plast Surg 2001; 54:665-74. 
20. Kane J, Morris S, Jackson T, Woods E. Significant hemangiomas and vascular malformations of the head and neck: clinical management and treatment outcomes. Ann Plast Surg1995; 35:133-43.

21. Frieden J, Eichenfield F, Esterly B, Geronemus R, Mallory B. American Academy of Dermatology guidelines of care for hemangiomas of infancy. $\mathrm{J}$ Am Acad Dermatol 1997; 37:631-7 